\title{
Pediatric Ependymoma: A Proteomics Perspective
}

\author{
GEORGE TH. TSANGARIS ${ }^{1}$, CHRISSA PAPATHANASIOU ${ }^{2}$, PANAGIOTIS G. ADAMOPOULOS ${ }^{3}$, \\ ANDREAS SCORILAS ${ }^{4}$, CONSTANTINOS E. VORGIAS ${ }^{4}$, \\ NEOFYTOS PRODROMOU ${ }^{3}$, FOTEINI TZORTZATOU STATHOPOULOU ${ }^{2}$, \\ DIMITRIOS J. STRAVOPODIS ${ }^{5}$ and ATHANASIOS K. ANAGNOSTOPOULOS ${ }^{1}$
}

\author{
${ }^{1}$ Proteomics Research Unit, Biomedical Research Foundation of the Academy of Athens, Athens, Greece; \\ ${ }^{2}$ Hematology/Oncology Unit, First Department of Pediatrics, University of Athens, \\ Aghia Sophia Children's Hospital, Athens, Greece; \\ ${ }^{3}$ Department of Neurosurgery, Aghia Sophia Children's Hospital, Athens, Greece; \\ ${ }^{4}$ Department of Biochemistry and Molecular Biology, Faculty of Biology, School of Sciences, \\ National and Kapodistrian University of Athens, Athens, Greece; \\ ${ }^{5}$ Department of Cell Biology and Biophysics, Faculty of Biology, School of Sciences, \\ National and Kapodistrian University of Athens, Athens, Greece
}

\begin{abstract}
Background/Aim: Proteomics based on highresolution mass spectrometry (MS) is the tool of choice for the analysis of protein presence, modifications and interactions, with increasing emphasis on the examination of tumor tissues. Application of MS-based proteomics offers a detailed picture of tumor tissue characteristics, facilitating the appreciation of different tumor entities, whilst providing reliable and fast results for therapeutic marker targeting and prognostic factor assessment. Through use of the high analytical resolution of nano-high-pressure liquid chromatography (nanoHPLC) and the high resolution of an Orbitrap Elite mass spectrometer, the present study aimed to provide knowledge on the proteome of the generally unknown entity of pediatric ependymal tumors. Materials and Methods: Ten resected specimens of childhood ependymoma were analyzed through a one-dimensional (ID) nanoLC-MS/MS approach. Method optimization steps were undertaken for both the sample preparation/protein extraction procedure and $L C$ parameters, aiming to achieve the highest possible identification rates. Results: Following method optimization, each nanoLC-MS/MS run resulted in identification of more than 5,000 proteins and more than 25,000 peptides for every
\end{abstract}

This article is freely accessible online.

Correspondence to: Dr. Athanasios K. Anagnostopoulos, Proteomics Research Unit, Biomedical Research Foundation of the Academy of Athens, Athens, Greece. Tel: +30 2106597383, Fax +30 2106597545, e-mail: atanagnost@bioacademy.gr

Key Words: Ependymoma, pediatric brain tumors, central nervous system tumors, nanoLC-MS/MS, proteomics, method development. analyzed sample, thus detailing the greater part of the ependymoma proteome. Identified proteins were found to spread throughout all known tumor categories regarding their molecular function and subcellular localization. Conclusion: Through the proposed nanoLC-MS/MS method herein we report, for the firs time, the ependymoma proteome database. A large number of similarities regarding proteome content are revealed compared to other two pediatric brain tumor entities; astrocytomas and medulloblastomas. Furthermore, through our approach, the majority of currently proposed markers for ependymoma (e.g. nucleolin, nestin, Ki67 and laminin subunit A2) as well as all major key players of the phosphoinositide 3-kinase pathway (seemingly implicated in ependymoma), were definitely detected.

Pediatric brain tumors are a leading cause of cancer-related death in children (1). The application of high-throughput technologies (e.g. proteomics, and genomics) to the analysis of these tumor types has generated an abundance of molecular information, while in parallel, adequately continuing to provide knowledge on both the biological and clinical aspects of this devastating disease affecting children (2).

Ependymoma, the third most common tumor in children, is thought to arise from ependymal cells in the wall of the cerebral ventricles or the spinal canal and therefore occurs most frequently in the posterior fossa or the spinal cord (3, 4). A variety of different sub-types of ependymomas have been identified, while the anaplastic variant seems to have the worse prognosis (5). Surgery remains the mainstay of treatment for ependymomas, while patients with posterior fossa ependymomas who have tumors amenable to gross total resection and are subsequently treated with radiotherapy, have a $70 \%$ or greater likelihood of long-term survival (6). 
Due to the heterogeneity of the disease, its biological characteristics remain largely unknown and prognostic factors are basically based on clinical and histological criteria (i.e. age, extent of tumor resection, and histological grade). Therefore, biological, both genetic and proteomic, alterations that could be used to further characterize these tumors as well as identifying molecules that can be used as targets for therapy, need to be discovered.

Proteins, being the major conductors of genetic information and the molecules that can better reflect the functional status of the cell, are key targets in central nervous system (CNS) cancer research (7). This is why the elucidation of protein expression and their modifications is crucial in brain cancer biology, also aiding in discovery of predictors of cancer risk, detection of biomarkers for early diagnosis and identification of therapeutic targets (8). Proteomics, working together with genomics, may be able to redefine current ependymoma classifications and management protocols (9).

In our previous work, we reported on protein/proteomic signatures of pediatric astrocytomas and pediatric medulloblastomas, having had the opportunity to unravel parts of the molecular signature of these two distinct malignancy types, based on experiments utilizing two-dimensional gelbased protein separation and protein quantitation via image analysis and western blotting. It must, however, be underlined that the two-dimensional gel-based approach is biased to identify relatively high-abundant proteins and may miss on low-abundance regulatory molecules, including signal transducers, membrane proteins etc. Currently, gel-free approaches, namely liquid chromatography-tandem mass spectrometry (LC-MS/MS), are being widely used for clinical tissue and cell-line analyses (10).

The aim of the current study was two-fold: (i) to develop a sensitive and reproducible LC-MS/MS method for full indepth proteomic screening of brain tumor tissues, and (ii) to build a high-confidence, in-depth proteome map from clinical cancer tissue specimens of ependymal origin, offering a first step towards their targeted protein validation in the clinical setting by the anticancer research community.

\section{Materials and Methods}

Tissue specimens. All samples were obtained from patients who underwent tumor resection surgery at Aghia Sophia Children's Hospital, Athens, Greece. All procedures were in accordance with approved human subject guidelines, and were approved by the Ethical Committee of the Athenian University. After informed consent was obtained from the patients' parents, samples were collected at initial diagnosis with no prior exposure to chemotherapy or radiation therapy.

All specimen analyzed in the study belonged to the cellular (WHO grade II) ependymoma subtype and all affected individuals were Caucasian (Table I). Resected tumors were stained with hematoxylin and eosin and examined by light microscopy.
Sample preparation. Prior to analyses, all tissue samples were washed in in a sucrose buffer (HEPES, $\mathrm{pH} 7.5,320 \mathrm{mM}$ sucrose, $1 \mathrm{mM}$ EDTA, $5 \mathrm{mM}$ dithioerythreitol, $1 \mathrm{mg} / \mathrm{ml}$ protease inhibitors) for removal of excess blood from tissue. Next, tissues were powderized through grinding in liquid nitrogen. Further homogenization for disruption of all remaining intact protein structures was performed by tip-sonication for three cycles, 18 seach, under $38 \%$ amplification. The lysis buffer used was $7 \mathrm{M}$ urea, 1.5 M Tris- $\mathrm{HCl}, 0.1 \mathrm{M}$ sodium dodecyl sulfate. The homogenate was left at room temperature for 1 $\mathrm{h}$ and centrifuged at $12,700 \times \mathrm{g}$ for $30 \mathrm{~min}$. De-salting was performed with Ultrafree-4 centrifugal filter unit (Millipore, Billerica, MA, USA). The protein content of the supernatant was determined using the Bradford quantification method. Protein extraction was sequentially performed by addition of $150 \mu \mathrm{l}$ of extraction buffer to the sample solution. Finally, $150 \mu \mathrm{g}$ of protein was further processed for peptide generation.

Peptide generation. Proteins were reduced, in solution, by incubation with $0.1 \mathrm{mM}$ DTE in Tris- $\mathrm{HCl} \mathrm{pH} 6.8$ for $30 \mathrm{~min}$ at $36^{\circ} \mathrm{C}$. Proteins were then alkylated by the addition of $0.05 \mathrm{mM}$ iodoacetamide for $30 \mathrm{~min}$ at room temperature in the dark. A trypsin solution (Roche, Hoffman-La-Roche, Basel, Switzerland) (final concentration $500 \mathrm{ng} / \mu \mathrm{l}$ ) was added to the sample at a trypsin to protein ratio of $1: 100$, mixed by pipetting and digestion took place overnight at $36^{\circ} \mathrm{C}$. The following day, trypsinization was terminated by the addition of $5 \%$ acetic acid ( $\mathrm{vol} / \mathrm{vol})$. Finally, peptidecontaining solutions were vacuum-dried for $1 \mathrm{~h}$ (until complete dryness). Powder was re-constituted in $100 \mu \mathrm{l}$ of water with $0.1 \%$ formic acid. After cleaning for impurities by filtering through a Millex ${ }^{\circledR}$ syringe-driven filter unit, nanoLC-MS/MS analysis followed.

One-dimensional nano-liquid chromatography (1D-nanoLC) separation. Peptides generated in the previous step were separated in an Ultimate3000 system nanoLC system (Dionex; Thermo Scientific, Bremen, Germany). Peptides were loaded onto a C-18 pre-column $(100 \mu \mathrm{m}$ inner diameter $\times 2 \mathrm{~cm} ; 100 \AA, 3-\mu \mathrm{m}$-bead-packed, Acclaim PepMap 100; Thermo Scientific) at $10 \mu \mathrm{l} / \mathrm{min}$ in $99.9 \%$ water with $0.1 \%$ formic acid. After $6 \mathrm{~min}$ of desalting, the pre-column was switched online with the analytical C-18 column $(75 \mu \mathrm{m} \times 50 \mathrm{~cm} ; 100$ $\AA$ A, 2- $\mu$ m-bead-packed Acclaim PepMap RSLC; Thermo Scientific) that was equilibrated with mobile phase A $(99.9 \%$ water with $0.1 \%$ formic acid). Elution time for all runs was $360 \mathrm{~min}$ for under a nonlinear gradient of mobile phase B $(99.9 \%$ acetonitrile with $0.1 \%$ formic acid) (Table II) at a constant $300 \mathrm{nl} / \mathrm{min}$ flow rate.

Orbitrap mass spectrometry. Mass spectra of eluted peptides were collected in an Orbitrap Elite mass spectrometer (Thermo Scientific) fitted with a nano-spray source, practically as previously described by our group $(11,12)$. The instrument was run in a data-dependent acquisition mode with the XCalibur ${ }^{\mathrm{TM}}$ v.2.2 SP1.48 software (Themo Scientific). Full-scan data were acquired on the $300-2,000 \mathrm{~m} / \mathrm{z}$ range under 60,000 resolution and a maximum injection time of $100 \mathrm{~ms}$. Data-dependent tandem MS for the 20 most intense ions was performed with higher-energy collision dissociation fragmentation in the Orbitrap at a resolving power of 15,000 and a collision energy of 36. Resulting fragments were analyzed on the Orbitrap; MS/MS spectra were acquired with 15,000 resolving power and a maximum injection time of $120 \mathrm{~ms}$. Measurements were performed using $\mathrm{m} / \mathrm{z}$ 445.120025 as lock mass. 
Table I. Patient characteristics.

\begin{tabular}{lc}
\hline Characteristic & Number/value \\
\hline No. of patients & \\
Total & 10 \\
Males & 6 \\
Females & 4 \\
Age (years) & \\
Median & 2.8 \\
Range & $0.6-4.8$ \\
ECOG PS, $\mathrm{n}$ & \\
0 & 1 \\
1 & 5 \\
2 & 4 \\
Histology, $\mathrm{n}$ & \\
Subependymoma (grade I) & 1 \\
Ependymoma (grade II), anaplastic & 9 \\
ependymoma (grade III) & \\
Stage, $\mathrm{n}$ & 2 \\
IIIA & 5 \\
IIIB & 3 \\
IV & \\
sCrea (mg/dl) & \\
Mean \pm SD & $0.53 \pm 0.1$ \\
T-bil (mg/dl) & \\
Mean \pm SD & $0.45 \pm 0.1$ \\
\hline
\end{tabular}

sCrea: Serum creatinine; T-bil: total bilirubin; ECOG PS: Eastern Coopeative Oncology Group Performance Status.

Data analysis. Raw data (each file consisting of an average of 72,000 spectra) were processed in Proteome Discoverer (version 1.4.0.388; Thermo Scientific), and searches were performed as described previously (11). Raw data were analyzed on the Homo sapiens UniProtKB/Swiss-Prot database $(20,200$ protein entries, reviewed 28-1-2016) using SequestHT under the following parameters: two maximum missed cleavages for trypsin; oxidation of methionine as variable modification; $10 \mathrm{ppm}$ peptide mass tolerance; and $0.05 \mathrm{ppm}$ fragment ion tolerance. Peptide spectral matches were validated using percolator based on $q$-values at $1 \%$ false discovery rate. Additional peptide filtering was performed based on Xcorr versus peptide charge values (percolator maximum Delta Cn was set at 0.05). Values of 2.2 for doubly-charged and 3.5 for triply-charged peptides were used. The minimum length of acceptable identified peptides was set as 6 amino acids.

Pathway analysis, functional clustering and classification. The Proteome Discoverer software was used to retrieve annotation information for identified proteins. Proteins were assigned their Gene Ontology (GO) terms and protein classification was performed based on these GO terms for biological process and subcellular localization. All identified proteins were analyzed; when more than one assignment was available, all the functional annotations were considered in the final results list. Theoretical molecular weight and pI were also used to classify proteins according to their physicochemical characteristics.

Functional analysis of the protein sets was performed using the Ingenuity Pathway Knowledge Base (Ingenuity Systems, Redwood City, CA, USA). Analysis resulted in identification of biological
Table II. Nano-high-pressure liquid chromatography gradient steps followed during the analysis.

\begin{tabular}{lcc}
\hline Retention time $(\mathrm{min})$ & Flow $(\mu 1 / \mathrm{min})$ & Mobile phase B $(\%)$ \\
\hline 0.000 & 0.300 & 4.0 \\
15.000 & 0.300 & 4.0 \\
265.000 & 0.300 & 25.0 \\
345.000 & 0.300 & 55.0 \\
410.000 & 0.300 & 80.0 \\
425.000 & 0.300 & 80.0 \\
460.000 & 0.300 & 4.0 \\
\hline
\end{tabular}

Mobile phase A: $99.9 \%$ acetonitrile, $0.1 \% \mathrm{H}_{2} \mathrm{O}$.

functions and diseases that were most significant to our protein data sets. Proteins showing highest expression in ependymoma samples (false discovery rate of $30 \%$ ) were considered for the analysis. The focus genes from all protein lists were overlaid onto a global molecular network, developed from information contained in the Ingenuity Pathway Knowledge Base and this generated networks based on the connectivity of the individual proteins according to their relevance with the tissues under study.

\section{Results}

In the present study, we embarked on analyzing the protein expression patterns of pediatric ependymoma tissues. Ten selected resected specimens were subjected to 1D-nanoLCMS/MS analysis and to strengthen the quality and reproducibility of protein profiling of each sample/tissue, analysis consisted of two technical replicates. The methodology followed in order to increase the number of identifications, and in parallel save on analysis time and quantity of material required, consisted of experimenting with several sample preparation procedures with regard to the protein extraction process, as well as testing in LC parameters.

Initially, tissues were prepared under two different approaches, the first consisting of tissue homogenization in liquid nitrogen followed by protein extraction in $0.1 \mathrm{M}$ Tris$\mathrm{HCl}$, supplemented with 4\% SDS and 0.1 M DTE (buffer A) and the second consisting of homogenization in Wheaton grind homogenizer followed by extraction in $8 \mathrm{M}$ urea in ammonium bicarbonate (50 mM) (buffer B) (Figure 1). Better results with regard to total protein identification numbers were achieved when the procedure including dissemination in liquid nitrogen and buffer A was followed.

Protocol optimization with regard to LC parameters included testing with a three-step non-linear gradient (Table II) against a classical linear 2-35\% mobile phase B gradient. Results indicated that an even distribution across the chromatographic run was achieved in the first, tailored method, compared to MS1 ions detected using linear gradients. Therefore, chromatographic profile design of the 


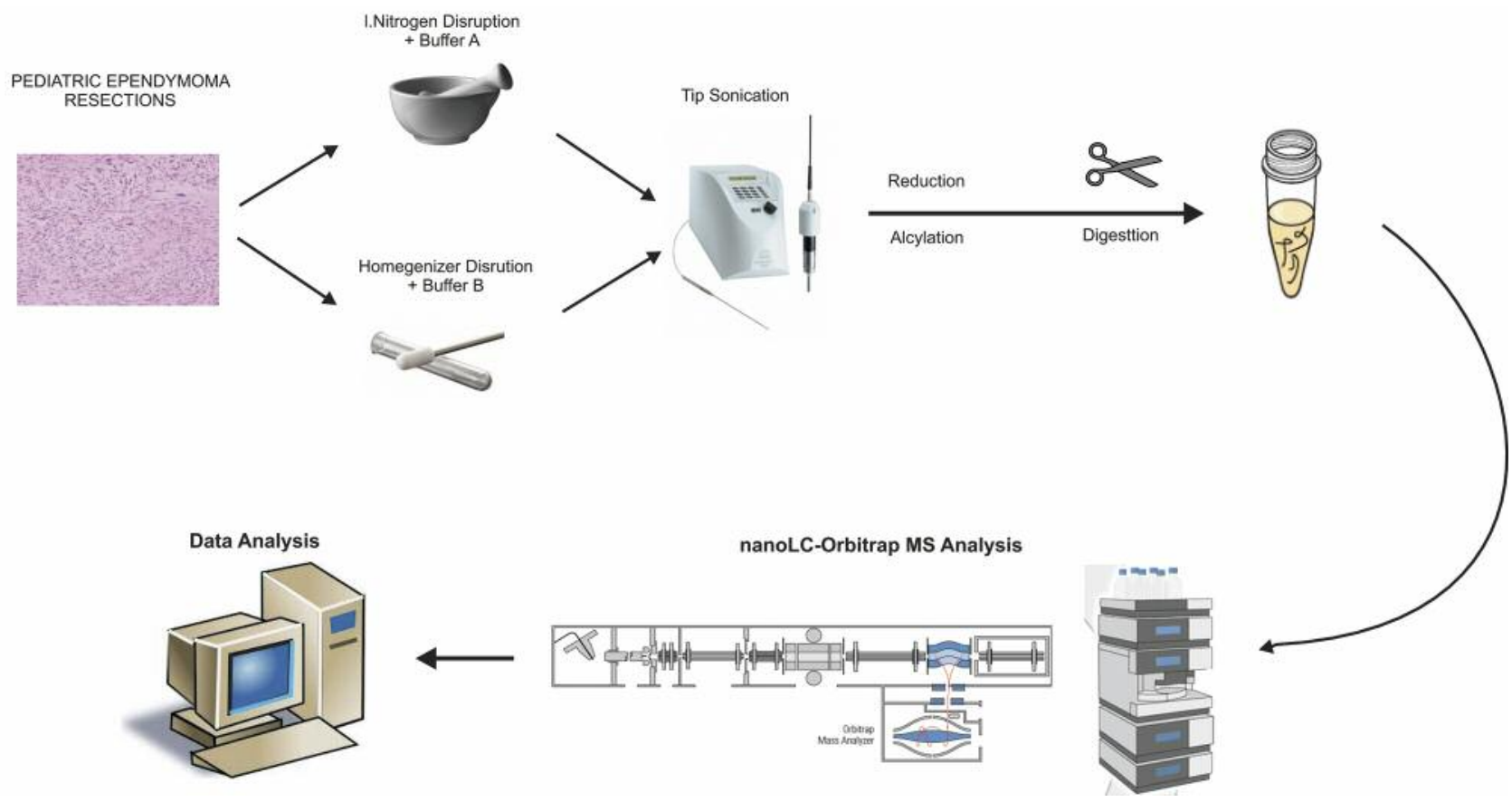

Figure 1. Deep proteome nano-high-performance liquid chromatography-tandem mass spectrometric (LC-MS/MS) analysis flowchart. Pediatric ependymoma resections were lysed under two different experimental approaches and proteins were extracted and digested by trypsin. Generated peptides were analyzed in Orbitrap Elite mass spectrometer. Method optimization steps to increase final protein identification rates were performed in sample lysis and LC parameters.

gradient offered a nearly constant number of unique peptides identified per minute of retention time. All optimized methods followed in the present study are described in detail in the Materials and Methods section.

After reaching a consensus with regard to optimizing the experimental procedure, all tissues were analyzed under the same protocol. The number of proteins identified in each tissue sample varied, with a mean of $4,000 \pm 150$ protein groups and a mean of $25,000 \pm 550$ peptides identified per sample. Only proteins (protein groups) identified/present in all samples were included in the final reference ependymoma protein database, consisting of 4,157 entries. An abstract of the final database showing protein coverage, unique peptides identified, peptide spectral matches, molecular weight and pI of identified proteins is given in Figure 2.

Furthermore, an investigation of the mRNA-miRNA interaction was carried out for each gene encoding the identified proteins. For this purpose, DIANA-TarBase v7.0, a database indexing more than half a million experimentally supported mRNA-miRNA interactions was used $(13,14)$. DIANA-TarBase v7.0 enables users to easily identify positive or negative experimental results, the utilized experimental methodology, experimental conditions including cell/tissue type and treatment. As a result, all experimentally validated miRNA:gene interactions for each human gene encoding the identified proteins is demonstrated in Table III.

Regarding GO terms, ependymoma proteins were grouped according to their biological process as well as localization. The majority of identified proteins (29\%) are involved in cell metabolic processes, while a significant number $(22.5 \%)$ are engaged in cell structure, $16.5 \%$ in localization procedures, $12 \%$ have biological regulatory roles, while others are connected to biogenesis $(7 \%)$, development and stimulatory or immune responses $(4 \%)$, or exert multiple functions $(3 \%)$. Less frequently represented are proteins with biological adhesion $(2 \%)$, proteins associated with apoptosis $(2 \%)$ and cell reproduction $(1 \%)$, as well as those associated with locomotion (1\%) (Figure 3A).

In terms of their cellular distribution, a large proportion of proteins were found to be localized in organelle lumen $(12.54 \%)$ and a greater number of proteins (14.8\%) were components of the nucleolus. The majority of pediatric ependymoma proteins were found to be cytoplasmic (18.66\%), while identified proteins were also present in other subcellular compartments such as the cytosol (13\%), the mitochondrion (10\%) and golgi apparatus (14\%), and $7 \%$ 


\begin{tabular}{|c|c|c|c|c|c|c|c|c|c|}
\hline 2 & Accession & Description & Coverage & \# Proteins & * Peptides & $\Rightarrow$ PSMs & \#AAs & $M W[\mathrm{kDa}]$ & cakc, pl \\
\hline 3 & AOAVT1 & Ubiquitin-like modifier-activating enzyme 6 OS=Homo sapiens GN=UBA6 $\mathrm{PE}=1 \mathrm{SV}=1$ - [UEA6_HUMAN] & 5,70 & 1 & 4 & 4 & 1052 & 117,9 & 6,14 \\
\hline 4 & AOFGRB & Extended synaptotagmin-2 OS=Homo sapiens GN=ESTT2 PE $=1$ SV $=1$ - [ESYT2_HUMAN] & 4,45 & 1 & 1 & 1 & 921 & 102,3 & 9,26 \\
\hline 5 & AOFGR9 & Extended synaptotagmin-3 OS=Homo sapiens GN=ESYT3 PE $=1$ SV $=1$ - [ESYT3_HUMAN] & 2,48 & 1 & 1 & 1 & 886 & 100,0 & 8,37 \\
\hline 6 & Aojows & UHRF1-binding protein 1-like OS=Homo sapiens $G N=U H R F 1 B P 1 L P E=1 S V=2$ - [UH1BL_HUMAN] & 1,64 & 1 & 1 & 1 & 1464 & 164,1 & 6,32 \\
\hline 7 & AOMBQ6 & Ig lambda-7 chain $\mathrm{C}$ region $0 \mathrm{~S}=$ Homo sapiens $G \mathrm{~N}=1 \mathrm{GLC} \quad \mathrm{PE}=1 \mathrm{SV}=2$ - [LAC7_HUMAN] & 32,08 & 4 & 2 & 17 & 106 & 11,3 & 8,28 \\
\hline 8 & AOMZ66: & Shootin-1 OS=Homo sapiens GN=KLAA1598 PE $=1 \mathrm{SV}=4$ - [SHOT1_HUMAN] & 3,33 & 1 & 1 & 1 & 631 & 71,6 & 5,33 \\
\hline 9 & ADPZZO & Putative ankyrin repeat domain-containing protein $20 \mathrm{AS}$ OS=Homo sapiens GN=ANKRD20A5P PE $=5 \mathrm{SV}=1-[\mathrm{A} 2 \mathrm{OAS}$ HUMAN] & 16,97 & 5 & 1 & 1 & 165 & 18,4 & 8,10 \\
\hline 10 & ALAAS6 & Rho GTPase-activating protein 10 OS=Homo sapiens GN=ARHGAP10 PE $=1 \mathrm{SV}=1$ - [RHG10_HUMAN] & 3,31 & 1 & 1 & 1 & 786 & 89,3 & 7,18 \\
\hline 11 & A116292 & Peroxidasin-like protein OS=Homo sapiens GN=PXDNL PE $=1 \mathrm{SV}=3$ - [PXDNL_HUMAN] & 1,57 & 1 & 1 & 1 & 1463 & 163,6 & 7,43 \\
\hline 12 & ALLTO & Acetolactate synthase-like protein OS=Homo sopiens GN=ILVBL PE $=1$ SV=2 - [ILVBL__HUMAN] & 9,34 & 1 & 3 & 4 & 632 & 67,8 & 8,15 \\
\hline 13 & AlLIAG & Immunoglobulin superfamily member 23 OS=Homo sapiens GN=1GSF23 PE $=2 \mathrm{SV}=2$ - [IGS23_HUMAN] & 22,40 & 1 & 1 & 1 & 192 & 20,6 & 6,58 \\
\hline 14 & A1)283 & 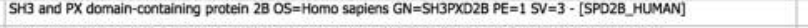 & 4,06 & 1 & 1 & 1 & 911 & 101,5 & 8,69 \\
\hline 15 & A21005 & Coiled-coll domain-containing protein 78 OS=Homo sapiens $\mathrm{GN}=\mathrm{CCDC78} \mathrm{PE}=2 \mathrm{SV}=1$ - [CCD78_HUMAN] & 3,65 & 1 & 1 & 1 & 438 & 48,5 & 8,16 \\
\hline 16 & A2PYHA & Probable ATP-dependent DNA helicase HFM1 OS=Homo sapiens GN=HFM1 PE=1 SV=2 -[HFM1_HUMAN] & 1,32 & 1 & 1 & 1 & 1435 & 162,5 & 7,09 \\
\hline 17 & A2RURG & Colled-coll domain-containing protein $144 \mathrm{~A}$ OS=Homo sapiens $G \mathrm{GN}=\mathrm{CCDC} 144 \mathrm{~A} \mathrm{PE}=1 \mathrm{SV}=1 \cdot$ [C144A_HUMAN] & 2,73 & 1 & 1 & 1 & 1427 & 165,0 & 5,36 \\
\hline 18 & AZVECQ S & SCO-spondin OS=Homo sapiens GN=SSPO PE=2 SV=1 - [SSPO_HUMAN] & 0,56 & 1 & 1 & 1 & 5147 & 547,1 & 6,02 \\
\hline 19 & A4DOSA L & Laminin subunit beta-4 OS=Homo sapiens $\mathrm{GN}=$ LAMB4 PE $=2 \mathrm{SV}=1$ - [LAMBA__HUMAN] & 1,59 & 1 & 1 & 1 & 1761 & 193,4 & 6,35 \\
\hline 20 & A4D1E1 2 & Zinc finger protein 804B OS=Homo sapiens GN=ZNFB04B PE $=2$ SV=2 - [Z804B_HUMAN] & 1,26 & 1 & 1 & 1 & 1349 & 152,5 & 8,54 \\
\hline 21 & A4DINS & Putative uncharacterized protein FU40288 OS=Homo saplens PE=2 SV=1 - [YG018_HUMAN] & 18,00 & 1 & 1 & 2 & 150 & 16,7 & 8,06 \\
\hline 22 & A4D155 & Ras-related proten Rab-19 OS=Homo sapiens GN=RAB19 PE=2 SV=2 - [RAB19_HUMAN] & 13,82 & 1 & 1 & 1 & 217 & 24,4 & 6,52 \\
\hline 23 & A4D1U4 & Proteeln LCHN OS=Homo saplens GN=LCHN PE=2 SV=1 - [LCHN_HUMAN] & 4,62 & 1 & 1 & 1 & 455 & 51,4 & 5,31 \\
\hline 24 & A40256 & Dual specficity protein phosphatase CDC14C OS=Homo saplens $\mathrm{GN}=\mathrm{CDC} 14 \mathrm{C}$ PE $=2 \mathrm{SV}=2$ - [C14C_HUMAN] & 5,96 & 1 & 1 & 1 & 554 & 63,3 & 8,57 \\
\hline 25 & A4FUG9 & EF-hand calclum-binding domain-containing protein 5 OS=Homo sapiens GN=EFCABS PE=1 SV=3 - [EFCBS_HUMAN] & 2,00 & 1 & 1 & 1 & 1503 & 173,3 & 5,82 \\
\hline 4140 & Q9roc2 & 2 EMILN-1 OS=Homo sapiens GN=EMILIN1 PE=1 SV=2 - [EMIL1_HUMAN] & 11,71 & 1 & 6 & 9 & 1016 & 106,6 & 5,15 \\
\hline 4141 & Q9vec9 & 9 Mitochondrial carrier homolog 2 OS=Homo sapiens GN=MTCH2 PE $=1 \mathrm{SV}=1$ - [MTCH2_HUMAN] & 11,22 & 1 & 2 & 3 & 303 & 33,3 & 7,97 \\
\hline 4142 & Q9Y6EO & Serine/threonine-protein kinase 24 OS=Homo sapiens GN=STK24 PE=1 SV=1- [STK24_HUMAN] & 2,93 & 1 & 1 & 1 & 443 & 49,3 & 5,69 \\
\hline 4143 & Q9Y6E2 & 2 Basic leucine zipper and W2 domain-containing protein 2 OS=Homo sapiens $\mathrm{GN}=8 Z \mathrm{ZW} 2 \mathrm{PE}=1 \mathrm{SV}=1$ - [BZW2_HUMAN] & 11,46 & 1 & 1 & 1 & 419 & 48,1 & 6,68 \\
\hline 4144 & Q97613 & 1. Epsin-1 OS=Homo sapiens GN=EPN1 PE=1 SV=2 - [EPN1_HUMAN] & 3,99 & 1 & 1 & 1 & 576 & 60,3 & 4,83 \\
\hline 4145 & Q9Y6k5 & 5 2'-5'-oligoadenylate synthase 3 OS=Homo sapiens GN=OAS3 PE $=1 \mathrm{SV}=3$ - [OAS3_HUMAN] & 0,92 & 1 & 1 & 1 & 1087 & 121,1 & 8,40 \\
\hline 4146 & Q9Y6L6 & 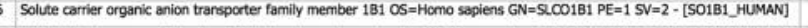 & 2,75 & 1 & 1 & 1 & 691 & 76,4 & 8,57 \\
\hline 4147 & Q9Y6M9 & 9 MAOH dehydrogenase [ubiquinone] 1 beta subcomplex subunit 9 OS=Homo sepiens GN=NDUFBg PE=1 SV=3 - [NDUB9_HUM, & 15,64 & 1 & 2 & 2 & 179 & 21,8 & 8,38 \\
\hline 4148 & Q9Y6N5 & 5 Sulfide:quinone oxidoreductase, mitochondrilal OS=Homo saplens GN=SQRDL PE $=1 \mathrm{SV}=1 \cdot$ [SQRD_HUMAM] & 3,11 & 1 & 1 & 1 & 450 & 49,9 & 9,11 \\
\hline 4149 & Q9Y6N6 & 5 Laminin subunt gamma-3 OS=Homo saplens GN=LAMC3 PE=1 SV=3 - [LAMC3_HUMAN] & 5,59 & 1 & 4 & 6 & 1575 & 171,1 & 6,58 \\
\hline 4150 & Q9Y6Q2 & 2 Storin-1 OS=Homo sapiens GN=STON1 PE $=1$ SV $=2 \cdot$ [STON1_HUMAN] & 2,72 & 1 & 1 & 1 & 735 & 83,1 & 6,20 \\
\hline 4151 & Q9Y6Q9 & 9 Nuclear receptor coactivator 3 OS=Homo sapiens GN=NCOA3 PE=1 SV=1 - [NCOA3_HUMAN] & 1,33 & 1 & 1 & 1 & 1424 & 155,2 & 7,47 \\
\hline 4152 & Q9Y6RO & Numb-like protein OS=Homo sapiens GN=NUMBL PE $=1$ SV $=1$ - [NUMBL__HUMAN] & 3,78 & 1 & 1 & 1 & 609 & 64,9 & 8,85 \\
\hline 4153 & Q9Y6U3 & 3 Adseverin OS=Homo saplens GN=SCIN PE=1 SV $=4$ - [ADSV_HUMAN] & 27,27 & 1 & 11 & 12 & 715 & 80,4 & 5,71 \\
\hline 4154 & Q9Y6W5 & 5 Wiskott:Aldrich syndrome protein family member 2 OS=Homo saplens GN=WASF2 $\mathrm{PE}=1 \mathrm{SV}=3$ - [WASF2_HUMAN] & 3,82 & 1 & 1 & 1 & 498 & 54,3 & 5,53 \\
\hline 4155 & Q9\%6x4 & 4 Soluble lamin-associated protein of $75 \mathrm{kDa}$ OS=Homo Sapiens $G N=F A M 169 \mathrm{APE}=1 \mathrm{SV}=2$ - [F169A_HUMAN] & 4,48 & 1 & 2 & 2 & 670 & 74,9 & 4,60 \\
\hline 4156 & Q9Y6X6 & 5 Unconventional myosin-XVI OS=Homo sapiens GN=MYO16 PE $=15 \mathrm{SV}=3$ - [MYO16_HUMAN] & 0,86 & 1 & 1 & 1 & 1858 & 206,0 & 6,81 \\
\hline 4157 & Q9Y627 & 7. Collectin-10 OS=Homo sapiens GN=COLEC10 PE =2 SV=2 - [COL10_HUMAN] & 4,69 & 1 & 1 & 1 & 277 & 30,7 & 7,33 \\
\hline
\end{tabular}

Figure 2. Final protein database of pediatric ependymoma. Only proteins (protein groups) identified/present in all samples ( $n=10)$ were included in the final reference ependymoma protein database, consisting of 4,157 entries. An Excel file form (an exemplary abstract is shown for reasons of convenience and comprehension), is presented including accession numbers of identified proteins (according to UniProt), name and description, sequence coverage, number of unique peptides, number of protein's amino acid residues (AAs), protein molecular weight (MW) and protein isoelectric point (pI).

were membranous. Ten percent of identified proteins were extracellular, as well as comprising proteins of the endoplasmic reticulum (Figure 3B).

Ependymoma proteins were further clustered according to their biophysical characteristics; the assessed theoretical pI values predicted an even protein accumulation in both the acidic region (pI 4-7) and pI 8-10 region (Figure 3C).

The ependymoma protein database was further analyzed through the Ingenuity Pathway Knowledge Base. By this functional tool, protein biological functions and/ diseases that are most significant to the datasets are identified. The rank product list, representing proteins present in the ependymoma analyzed samples, generated the following top networks: (i) Cellular function and maintenance, post-translational modification, protein folding (Ingenuity Pathway analysis internal score, 60); (ii) dermatological diseases and conditions, inflammatory disease, cancer (score, 41); and (iii) cancer, hematological disease, reproductive system disease (score, 39). Cancer, dermatological diseases and gastrointestinal diseases are the main diseases connected to the list. The top canonical pathways associated with high significance are the 14-3-3-mediated signaling ( $p$-value $3.25^{\mathrm{e}-}$ $\left.{ }^{16}\right)$ and the protein ubiquitination pathway ( $p$-value $\left.1.2^{\mathrm{e}-11}\right)$.

Several networks, implicating the analyzed molecules, showing protein-protein interactions, were generated by the software. A very interesting network implicating identified molecules significant in cell death of ependymal tissues is presented in Figure 4.

\section{Discussion}

In the present study, by employing a modified cutting-edge one-dimensional shotgun proteomic approach, we aimed to unveil for the first time the proteome of a pediatric brain tumor entity, generally unknown regarding its molecularproteomic biological traits, pediatric ependymoma. 
Table III. List of experimentally validated mRNA-miRNA interactions as obtained by DIANA-TarBase. The official names of the human genes encoding for every protein of Figure 2 are demonstrated in the first column, whereas all human microRNAs that are experimentally validated to interact with their mRNA transcripts are shown in the second column. The prediction score for each mRNA-miRNA interaction is presented in parentheses next to each microRNA.

\begin{tabular}{|c|c|}
\hline Official gene ID & Experimentally validated microRNAs \\
\hline UBA6 & $\begin{array}{l}\text { miR-429 (0.961), miR-200c-3p (0.932), miR-200b-3p (0.926), miR-129-5p (0.918), miR-1302 (0.873), miR-590-3p (0.866), } \\
\text { miR-522-3p (0.856), miR-93-3p (0.817) }\end{array}$ \\
\hline ESYT2 & miR-124-3p (0.965), miR-124-3p (0.965), miR-374a-5p (0.818) \\
\hline$U H R F 1 B P 1 L$ & miR-489 (0.711), miR-200b-3p (0.652), miR-200c-3p (0.64), miR-374b-5p (0.592), miR-2110 (0.507), miR-21-5p (0.453) \\
\hline ARHGAP10 & miR-16-5p (0.505), miR-1305 (0.483), miR-20b-3p (0.477) \\
\hline$S H 3 P X D 2 B$ & $\begin{array}{l}\text { miR-1 (0.939), miR-29b-3p (0.772), miR-29c-3p (0.76), miR-29a-3p (0.755), miR-27a-3p (0.666), miR-17-3p }(0.66), \\
\text { miR-432-5p (0.649), miR-622 (0.629), miR-22-3p (0.557), miR-27a-5p }(0.557), \text { miR-24-3p }(0.501)\end{array}$ \\
\hline MTCH2 & $\begin{array}{l}\text { miR-150-5p (0.99), miR-3179 (0.739), miR-335-3p (0.725), miR-148b-3p (0.697), miR-152 (0.69), miR-625-5p }(0.675) \\
\text { miR-501-3p (0.659), miR-140-5p (0.617), miR-502-3p (0.579), miR-196a-5p }(0.489), \text { miR-7-5p }(0.467)\end{array}$ \\
\hline STK24 & miR-155-5p (0.498) \\
\hline OAS3 & 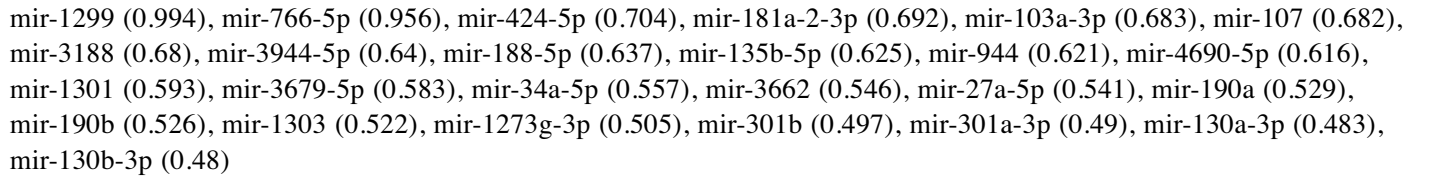 \\
\hline NDUFB 9 & miR-22-5p (0.567), miR-335-3p (0.459) \\
\hline$L A M C 3$ & miR-122-5p (0.667) \\
\hline$N U M B L$ & $\begin{array}{l}\text { miR-34a-5p (0.999), miR-449a (0.999), miR-122-5p (0.742), miR-122-5p (0.742), miR-3127-3p (0.639), } \\
\text { miR-129-2-3p (0.577), miR-182-5p (0.516), miR-221-5p (0.466) }\end{array}$ \\
\hline$S C I N$ & miR-330-5p $(0.733)$ \\
\hline WASF2 & hsa-miR-7-5p (0.478) \\
\hline
\end{tabular}

With regard to proteome optimization steps employed in the present study, aiming at reaching greater protein coverage without compromising on speed of analysis and sensitivity, we herein propose a universal sample preparation method for for nanoLC-MS/MS analysis of pediatric brain tissues, which can, under certain conditions, be applied to all experiments on brain tissue specimens, whether malignant or not. Optimization steps were assessed on two parameters: (i) sample preparation by two different extraction buffers, and (ii) LC gradient conditions.

Under the concentrations provided, the proposed lysis buffer (buffer A) in combination with tissue severance in liquid nitrogen was optimal in attaining maximal dissociation of protein complexes, with adequate protein extraction, as well as solubility of the extracted material.

Regarding experimentation on LC parameters, it is well known that for complex peptide mixtures, conventional linear gradients produce an unequal spread of peptides, and peptide distributions deviate considerably from uniformity, with larger numbers of peptides eluting in the middle of the run, and relatively few peptides eluting in the beginning and towards the end of the gradient time. In the present study, we propose a three-step non-linear gradient that seems to provide an even distribution of all eluted ions across the chromatographic run compared to MS1 ions produced using linear gradients.
Under a constant flow rate of $300 \mathrm{nl} / \mathrm{min}$, the improved chromatographic parameters were set to begin at $4 \%$ acetonitrile increasing linearly to $25 \%$ over $250 \mathrm{~min}$, then to $55 \%$ over $80 \mathrm{~min}$, and finally to $80 \%$ over $30 \mathrm{~min}$. We also experimented on elution time duration and reached the conclusion that a clear and linear correlation between the chromatographic peak capacity in peptide elution (15) was achieved at $360 \mathrm{~min}$ of total elution time.

By following the above experimental protocol modifications regarding protein extraction and chromatographic parameters, we developed an LC-MS/MS method able to deliver more than 5,000 protein entries belonging to 4,155 protein groups and 25,345 peptides, thus mapping in-depth for the first time the greater part of the proteome of this pediatric-type human brain malignancy.

Previously, we had undertaken steps in studying the other two major pediatric brain tumor malignancies: pediatric astrocytoma (16) and pediatric medulloblastoma (15), by means of proteomics technologies. The current series of analyzed samples sheds light on similarities in protein patterns throughout the panel of the three pediatric brain tumor malignancies. It is disappointing that we cannot yet discuss in-depth differences of protein content (in a quantitative manner) between the three types, since the proteomic technologies employed for astrocytomas and 


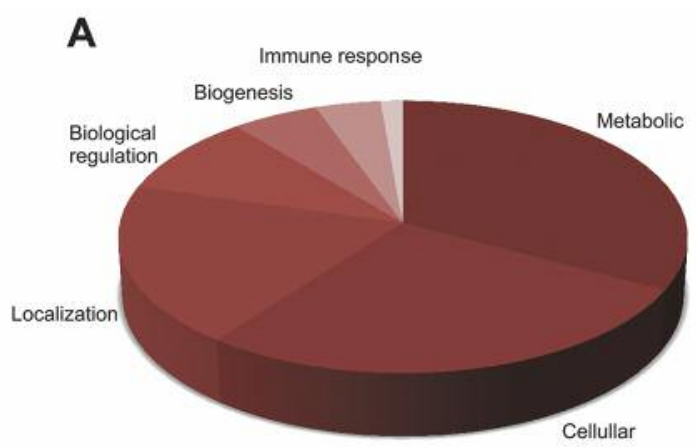

B
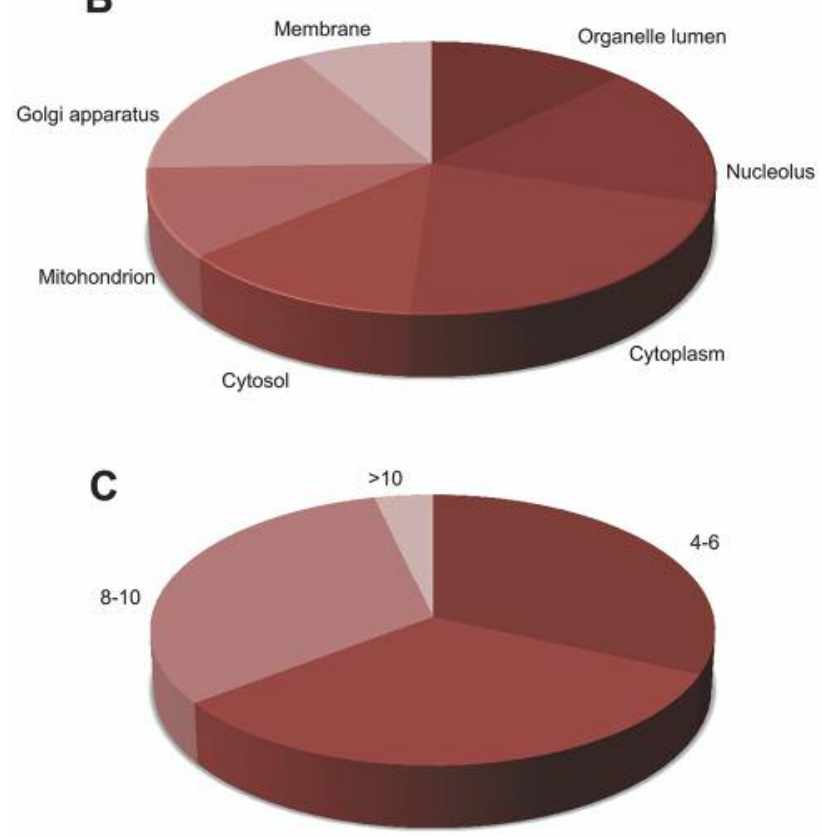

$6-8$

Figure 3. Classification of ependymoma proteins according to their biological process (A) and subcellular localization $(B)$. The distribution frequencies with regard to the specified categories within the given charts are indicated as a percentage of the total number of protein entries. Physicochemical characteristics were also utilized to further classify the ependymoma proteins according to their $\mathrm{pI}(\mathrm{C})$.

medulloblastomas far lacked the forward/analytical character of the nanoLC-MS/MS procedure described herein.

Regarding the biological traits of the material under study, all major components of the mitogen-activated protein kinase pathway that had been reported to be de-regulated in grade 1 tumors (astrocytomas) (Q13418, Q04759, P12931, P63104, Q04917, P27348, P28482) by us and others (16-18), are present in the final list of ependymomas, further confirming the intermediate character of this type of malignancy (5).

Furthermore, regarding expression of heat-shock molecules, similarities were found in heat-shock protein 90 (P08238),
60-kDa heat-shock protein (P10809) and 70-kDa heat-shock protein (P34932), which were found to be equally expressed in in low-grade gliomas (astrocytomas) and ependymomas, consistent with the general scheme that heat shock proteins are expressed as a response to various stress stimuli, including cancer. However, heat-shock protein 71-kDa (P11142), and heat-shock protein beta (P04792) and 90-alpha (P07900) were exclusively expressed in ependymomas.

Interestingly, both prohibitin (P35232), prohibitin 2 (Q99623), glial fibrillary acidic protein (GFAP; P14136) and vimentin (P08670) were among the proteins expressed in ependymomal tissues, similarly to astrocytomas. Prohibitin, a pleiotropic protein overexpressed in several tumor types, has been implicated in the regulation of cell proliferation, invasive migration and survival, and the ERK pathway (19). Positivity of tumors for both immunohistochemical markers vimentin and GFAP revealed a similar character of ependymoma to that of astrocytoma, revealing a high requirement for chaperoning activity inside tumor cells, enhanced by the presence of heat-shock proteins $(20,21)$.

Expression of the galectin protein family is in tight correlation with human gliomas and relevant to the modulation of invasion of tumor astrocytes into brain parenchyma (22). Galectins are glycan-binding proteins highly expressed in several tumor types (including brain neoplasms) and have been correlated with adverse prognosis of certain tumor types; strong expression of galectin-3 has been found in astrocytomas and medulloblastomas (23). In our study, galectins 1, 3, 8, 9 and 9b were found to be present in our analyzed series of patients. Due to their unique structure, galectins can oligomerize forming lattices upon binding to multivalent oligossacharides and influence several pathological events, such as tumorigenesis, invasion and metastasis (24)

Peroxiredoxins I-VI have recently been shown to have a role in the tumorigenesis of astrocytic brain tumors $(25,26)$. The presence of all perixoredoxin molecules, except for peroxideroxin-3, was noted in our studied ependymoma samples, in contrast to Haapasalo et al. who reported absence of perixiredoxin 4 (26). Peroxiredodin presence advocates the presence of defense in oxidative damage, to surpass the effect of oxidative stress taking place in ependymoma tissues.

A similar outline was depicted for similarities and differences regarding ependymal tissues and medullostoma. Coronin 1A, $1 \mathrm{~B}, 1 \mathrm{C}$ and $2 \mathrm{~B}$ were identified as components of epeyndymoma tissues. Coronin 1B (Q9BR76) is known to be implicated in contractility at adherens junctions and therefore influences apoptotic cell extrusion (27). Furthermore, coronin 1A (P31146), a newly identified p53 transcriptional target and a homotrimeric F-actin binding protein, important for cell migration and brain morphogenesis, whose expression has been implicated in diffuse glioma malignancies $(28,29)$ was found to be part of the ependymomal proteome; this specific molecule was also present in our previous analysis of medulloblastoma tissues (17). 


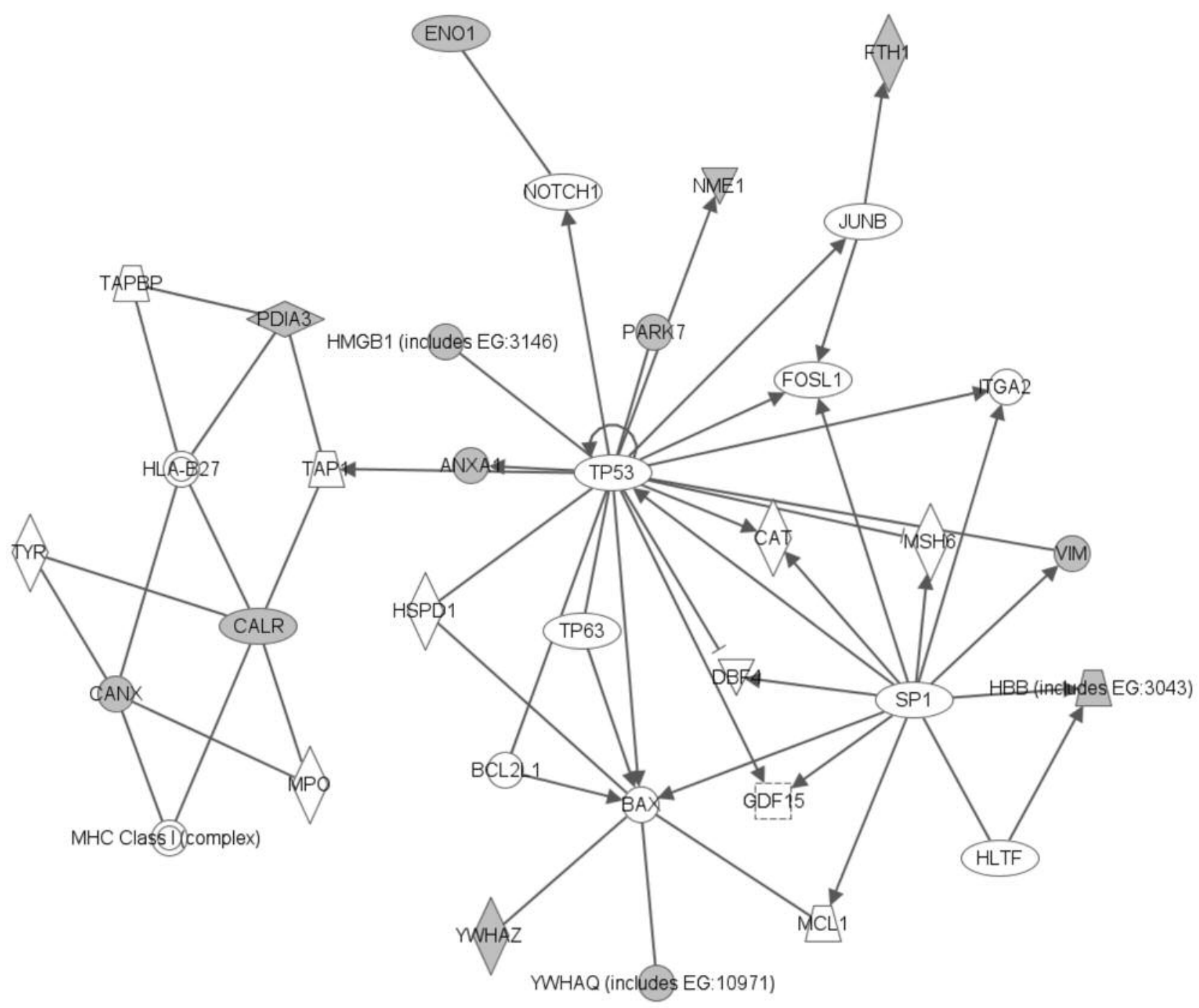

Figure 4. Signaling pathway network mined for proteins identified in pediatric ependymoma. Construction of the diagram was performed by the Ingenuity Pathway Analysis software, as described in the Materials and Methods section. Gray nodes indicate focus genes/proteins of ependymoma. Solid lines represent direct interactions between proteins. Direct interactions are defined as those where two proteins directly contact each other, with no intermediate step and usually comprise chemical modifications.

Furthermore, drebrin (Q16643), an actin-binding protein involved in the regulation of actin filament organization, playing a significant role in cell motility and having been implicated in glioma cell invasiveness (28), has equally been found to be expressed in medulloblastoma and ependymoma tissues. Both drebrin and synaptophysin (P08247) are neuronal synaptic markers playing roles in microglial activation prior to any visible signs of neuronal cell death, including neuronal cleaved caspase-3 activation (31).

Similarly to medulloblastoma, programmed cell death 6interacting protein (Q8WUM4), a key regulator of tumor growth and angiogenesis implicated in the PI3K pathway, protein lyric (Q86UE4), a protein that activates the nuclear factor- $x \mathrm{~B}$ transcription factor and promotes anchorageindependent growth of immortalized melanocytes and astrocytes and secreted protein acidic and rich in cysteine (SPARC) (P09486), an inducer of neuronal differentiation as a cell defense mechanism against tumor transformation, were all found to be present in ependymoma tissues (32-34).

Overall, all putative biological markers proposed through genomic studies/approaches identified in larger cohorts of samples including nucleolin (P19338) (35), Ki-67 (P46013) (36), nestin (P48681) (37) and laminin subunit A2 (P24043) (38) were identified as being present in the our analyzed 
samples, thus further confirming the analytical power of the method of analysis proposed herein.

The PI3K pathway is one of the most commonly activated pathways in cancer, including glioma and medulloblastoma cancer types $(17,39,40)$. PI3Ks are lipid kinases that transduce signals from growth factors and cytokines influencing diverse biological functions, including cellular proliferation, survival, and motility. The PI3K pathway has been reported to be activated in a large number of ependymoma cases examined by polymerase chain reaction and immunohistochemical analyses (41). It is of great importance that the nanoLCMS/MS method developed in the present study allows for definite identification of key molecules of the specific pathway, thus allowing for further confirmation (in a quantitative manner) of deregulation of the specific molecules once compared to tissues that are non-malignant (manuscript in preparation). More specifically, proteins integrin (P05106), MAPK1 (P28482), MEK1/2 (Q2750), p7056K (P23443), NF$x \mathrm{~B}$ (P19838) and B-cell lymphoma 2-like protein (Q9BXK5) were all present in the final protein list of ependymomas, reported in our present study.

Whether future molecular pathophysiology experiments lead research of this specific brain malignancy towards the PI3K pathway as a potential therapeutic target and potential prognostic marker for ependymoma, or towards any other relevant pathway or isolated molecule or panel of molecules, one fact is certain: proteomics, and more specifically, enhanced in-depth nanoLC-MS/MS analysis, will provide the tools for assessing results of all molecular approaches in an easily accessible and highly reproducible manner.

\section{Acknowledgements}

The Authors would like to thank all patients and their families without whom advance in pediatric brain tumor research would not be possible.

\section{References}

1 Firme MR and Marra MA: The molecular landscape of pediatric brain tumors in the next-generation sequencing era. Curr Neurol Neurosci Rep 14(9): 474, 2014.

2 Anagnostopoulos AK and Tsangaris GT: Proteomics of pediatric brain tumors. Exp Reviews Proteomics 11(5): 641-648, 2014.

3 de Bont JM, den Boer ML, Kros JM, Passier MM, Reddingius RE, Smitt PA, Luider TM and Pieters R: Identification of novel biomarkers in pediatric primitive neuroectodermal tumors and ependymomas by proteome-wide analysis. J Neuropathol Exp Neurol 66(6): 505-516, 2007.

4 Merchant TE and Fouladi M: Ependymoma: New therapeutic approaches including radiation and chemotherapy. J Neurooncol 75: 287Y99, 2005.

5 de Bont JM, Packer RJ, Michiels EM, den Boer ML and Pieters R: Biological background of pediatric medulloblastoma and ependymoma: a review from a translational research perspective. Neuro Oncol 10(6): 1040-1060. 2008
6 Nieder C, Andratschke NH and Grosu AL: Re-irradiation for recurrent primary brain tumors. Anticancer Res 36(10): 49854995, 2016.

7 Da Costa GG, Gomig TH, Kaviski R, Santos Sousa K, Kukolj C, De Lima RS, De Andrade Urban C, Cavalli IJ and Ribeiro EM: Comparative proteomics of tumor and paired normal breast tissue highlights potential biomarkers in breast cancer. Cancer Genomics Proteomics 12(5): 251-261, 2015.

8 Weidle UH, Birzele F, Kollmorgen G and Rüger R: Dissection of the process of brain metastasis reveals targets and mechanisms for molecular-based intervention. Cancer Genomics Proteomics 13(4): 245-258, 2016.

9 Anagnostopoulos AK, Vougas K, Kolialexi A, Mavrou A, Foundoulakis $M$ and Tsangaris GT: The protein profile of the human immature T-cell line CCRF-CEM: Cancer Genomics Proteomics 2(4): 271-300. 2005.

10 Polisetty RV, Gautam P, Sharma R, Harsha HC, Nair SC, Gupta MK, Uppin MS, Challa S, Puligopu AK, Ankathi P, Purohit AK, Chandak GR, Pandey A and Sirdeshmukh R: LC-MS/MS analysis of differentially expressed glioblastoma membrane proteome reveals altered calcium signaling and other protein groups of regulatory functions. Mol Cell Proteomics 11(6): M111.013565, 2012.

11 Anagnostopoulos AK, Stravopodis DJ and Tsangaris GT: Yield of 6,000 proteins by $1 \mathrm{D}$ nLC-MS/MS without pre-fractionation. J Chromatogr B Analyt Technol Biomed LifeSci. pii: S15700232(16)30656-0. 2016.

12 Velentzas AD, Anagnostopoulos AK, Velentzas PD, Mpakou VE, Sagioglou NE, Tsioka MM, Katarachia S, Manta AK, Konstantakou EG, Papassideri IS, Tsangaris GT and Stravopodis DJ: Global proteomic profiling of Drosophila ovary: a highresolution, unbiased, accurate and multifaceted analysis. Cancer Genomics Proteomics 12(6): 369-384, 2015.

13 Paraskevopoulou MD, Vlachos IS and Hatzigeorgiou AG: DIANA-TarBase and DIANA Suite Tools: Studying experimentally supported microRNA targets. Curr Protoc Bioinformatics 55: 12.14.1-12.14.18, 2016.

14 Vlachos IS, Paraskevopoulou MD, Karagkouni D, Georgakilas G, Vergoulis T, Kanellos I, Anastasopoulos IL, Maniou S, Karathanou K, Kalfakakou D, Fevgas A, Dalamagas T and Hatzigeorgiou AG: DIANA-TarBase v7.0: indexing more than half a million experimentally supported miRNA:mRNA interactions. Nucleic Acids Res 43(Database issue): p. D153-159, 2015.

15 Thakur SS, Geiger T, Chatterjee B, Bandilla P, Fröhlich F, Cox $\mathrm{J}$ and Mann M: Deep and highly sensitive proteome coverage by LC-MS/MS without prefractionation. Mol Cell Proteomics 10(8): M110.003699, 2011.

16 Anagnostopoulos AK, Dimas KS, Papathanassiou C, Braoudaki M, Anastasiadou E, Vougas K, Karamolegou K, Kontos H, Prodromou N, Tzortzatou-Stathopoulou F and Tsangaris GT: Proteomics studies of childhood pilocytic astrocytoma. J Proteome Res 10(5): 2555-2565, 2011.

17 Anagnostopoulos AK, Papathanassiou C, Karamolegou K, Anastasiadou E, Dimas KS, Kontos H, Koutsopoulos A, Prodromou N, Tzortzatou-Stathopoulou F and Tsangaris GT: Proteomic studies of pediatric medulloblastoma tumors with $17 \mathrm{p}$ deletion. J Proteome Res 14(2): 1076-1088, 2015.

18 Pfister S, Janzarik WG, Remke M, Ernst A, Werft W, Becker N, Toedt G, Wittmann A, Kratz C, Olbrich H, Ahmadi R, Thieme B, Joos S, Radlwimmer B, Kulozik A, Pietsch T, Herold-Mende 
C, Gnekow A, Reifenberger G, Korshunov A, Scheurlen W, Omran $\mathrm{H}$ and Lichter P: BRAF gene duplication constitutes a mechanism of MAPK pathway activation in low-grade astrocytomas. J Clin Invest 118(5): 1739-1749, 2008.

19 Cao Y, Liang H, Zhang F, Luan Z, Zhao S, Wang XA, Liu S, Bao R, Shu Y, Ma Q, Zhu J and Liu Y: Prohibitin overexpression predicts poor prognosis and promotes cell proliferation and invasion through ERK pathway activation in gallbladder cancer. J Exp Clin Cancer Res 35: 68, 2016.

20 Fernando G, Paul F, Laura J, Alejandra AM, Gabriela M and Alberto PL: Is the WNT/ $\beta$ catenin signalling pathway activated in seminoma? An immunohistochemical study. J Cancer Res Ther 12(2): 1075-1079, 2016.

21 Palm T, Figarella-Branger D, Chapon F, Lacroix C, Gray F, Scaravilli F, Ellison DW, Salmon I, Vikkula M and Godfraind C: Expression profiling of ependymomas unravels localization and tumor grade-specific tumorigenesis. Cancer 115(17): 3955-3968, 2009.

22 Rorive S, Belot N, Decaestecker C, Lefranc F, Gordower L, Micik S, Maurage CA, Kaltner H, Ruchoux MM, Danguy A, Gabius HJ, Salmon I, Kiss R and Camby I: Galectin-1 is highly expressed in human gliomas with relevance for modulation of invasion of tumor astrocytes into the brain parenchyma. Glia 3: 241-255, 2001,

23 Borges CB, Bernardes ES, Latorraca EF, Becker AP, Neder L, Chammas R, Roque-Barreira MC, Machado HR and de Oliveira RS: Galectin-3 expression: a useful tool in the differential diagnosis of posterior fossa tumors in children. Childs Nerv Syst 27(2): 253-257, 2011.

24 Pereira JX, Azeredo MC, Martins FS, Chammas R, Oliveira FL, Santos SN, Bernardes ES, El-Cheikh MC: The deficiency of galectin-3 in stromal cells leads to enhanced tumor growth and bone marrow metastasis. BMC Cancer 16: 636, 2016.

25 Jarvela S, Rantala I, Rodriguez A, Kallio H, Parkkila S, Kinnula VL, Soini Y and Haapasalo H: Specific expression profile and prognostic significance of peroxiredoxins in grade II-IV astrocytic brain tumors. BMC Cancer 22: 100-104, 2010.

26 Haapasalo T, Nordfors K, Järvelä S, Kok E, Sallinen P, Kinnula VL, Haapasalo HK and Soini Y: Peroxiredoxins and their expression in ependymomas. J Clin Pathol 66(1): 12-17, 2013.

27 Michael M, Meiring JC, Acharya BR, Matthews DR, Verma S, Han SP, Hill MM, Parton RG, Gomez GA and Yap AS: Coronin $1 \mathrm{~B}$ reorganizes the architecture of F-actin networks for contractility at steady-state and apoptotic adherens junctions. Dev Cell 37(1): 58-71, 2016.

28 Di Giovanni S, Knights CD, Rao M, Yakovlev A, Beers J, Catania J, Avantaggiati ML and Faden AI: The tumor suppressor protein $\mathrm{p} 53$ is required for neurite outgrowth and axon regeneration. EMBO J 17: 4084-4096, 2006.

29 Thal D, Xavier CP, Rosentreter A, Linder S, Friedrichs B, Waha A, Pietsch T, Stumpf M, Noegel A and Clemen C: Expression of coronin-3 (coronin-1C) in diffuse gliomas is related to malignancy. J Pathol 214(4): 415-424, 2008.

30 Terakawa Y, Agnihotri S, Golbourn B, Nadi M, Sabha N, Smith CA, Croul SE and Rutka JT: The role of drebrin in glioma migration and invasion. Exp Cell Res 319(4): 517-528, 2013.

31 Jebelli J, Hooper C and Pocock JM: Microglial p53 activation is detrimental to neuronal synapses during activation-induced inflammation: Implications for neurodegeneration. Neurosci Lett 583: 92-97, 2014.
32 Rho SB, Song YJ, Lim MC Lee SH, Kim B and Park SY: Programmed cell death 6 (PDCD6) inhibits angiogenesis through $\mathrm{PI} 3 \mathrm{~K} / \mathrm{mTOR} / \mathrm{p} 70 \mathrm{~S} 6 \mathrm{~K}$ pathway by interacting of VEGFR-2. Cell Signal 24(1): 131-139, 2012.

33 Emdad L, Sarkar D, Su ZZ, Randolph A, Boukerche H, Valerie $\mathrm{K}$ and Fisher PB: Activation of the nuclear factor kappa B pathway by astrocyte elevated gene-1: implications for tumor progression and metastasis. Cancer Res 66(3): 1509-1516, 2006.

34 Tai IT, Dai M, Owen DA and Chen LB: Genome-wide expression analysis of therapy-resistant tumors reveals SPARC as a novel target for cancer therapy. J Clin Invest 115: 1492-502, 2005.

35 Ridley L, Rahman R, Brundler MA, Ellison D, Lowe J, Robson K Prebble E, Luckett I, Gilbertson RJ, Parkes S, Rand V, Coyle B and Grundy RG: Multifactorial analysis of predictors of outcome in pediatric intracranial ependymoma. Neuro Oncol 10: 675-689, 2008.

36 Bennetto L, Foreman N, Harding B, Hayward R, Ironside J, Love $\mathrm{S}$ and Ellison D: Ki-67 immunolabelling index is a prognostic indicator in childhood posterior fossa ependymomas. Neuropathol Appl Neurobiol 24: 434-440, 1998.

37 Milde T, Hielscher T, Witt H, Kool M, Mack SC, Deubzer HE Oehme I, Lodrini M, Benner A, Taylor MD, von Deimling A, Kulozik AE, Pfister SM, Witt O and Korshunov A: Nestin expression identifies ependymoma patients with poor outcome. Brain Pathol 22: 848-860. 2012.

38 Witt H, Mack SC, Ryzhova M, Bender S, Sill M, Isserlin R Benner A, Hielscher T, Milde T, Remke M, Jones DT, Northcott PA, Garzia L, Bertrand KC, Wittmann A, Yao Y, Roberts SS, Massimi L, Van Meter T, Weiss WA, Gupta N, Grajkowska W, Lach B, Cho YJ, von Deimling A, Kulozik AE, Witt O, Bader GD, Hawkins CE, Tabori U, Guha A, Rutka JT, Lichter P, Korshunov A, Taylor MD and Pfister SM: Delineation of two clinically and molecularly distinct subgroups of posterior fossa ependymoma. Cancer Cell 20: 143-157, 2011.

39 Chakravarti A, Zhai G, Suzuki Y, Sarkesh S, Black PM, Muzikansky A and Loeffler JS: The prognostic significance of phosphatidylinositol 3-kinase pathway activation in human gliomas. J Clin Oncol 22: 1926-1933, 2004.

40 Hartmann W, Digon-Sontgerath B, Koch A, Waha A, Endl E, Dani I Denkhaus D, Goodyer CG, Sörensen N, Wiestler OD and Pietsch T: Phosphatidylinositol 30-kinase/AKT signaling is activated in medulloblastoma cell proliferation and is associated with reduced expression of PTEN: Clin Cancer Res 12: 3019-3027, 2006.

41 Rogers HA, Mayne C, Chapman RJ, Kilday JP, Coyle B and Grundy RG: PI3K pathway activation provides a novel therapeutic target for pediatric ependymoma and is an independent marker of progression-free survival. Clin Cancer Res 19(23): 6450-6460. 2013. 